\title{
A contribuição brasileira para pesquisa de vacinas contra o novo coronavírus
}

\section{The Brazilian contribution to research on vaccines against the new coronavirus}

Lúcia Renata Meireles de Souza ${ }^{1}$

Blima Fux ${ }^{1}$

Carolina Fiorin Anhoque ${ }^{1,2}$

\author{
${ }^{1}$ Universidade Federal do Espírito Santo. Vitória/ES, Brasil. \\ ${ }^{2}$ Hospital Universitário Cassiano Antônio Moraes. Vitória/ES, Brasil.
}

\begin{abstract}
Não é a primeira vez que o mundo enfrenta uma pandemia, mas os atuais avanços científicos abriram caminho para a produção em tempo recorde de vacinas. Cerca de 190 estavam em desenvolvimento em outubro de 2020, e quatro das dez vacinas que alcançaram a fase 3 entraram em teste de eficácia no Brasil ${ }^{1,2}$. Essas 4 candidatas utilizam as plataformas vacinais de vírus inativado, vetor viral não replicante ou RNA, retratando a evolução de diferentes gerações de vacinas ${ }^{3}$. A CoronaVac, da farmacêutica chinesa Sinovac, com transferência de tecnologia para o Instituto Butantan, é exemplo de vacina de primeira geração, utilizando o vírus SARS-CoV-2 inativado ${ }^{1,2,3}$. Por outro lado, a vacina da Universidade de Oxford (associada à farmacêutica britânica/sueca Astra-Zeneca), com transferência de tecnologia para Biomanguinhos/ Fiocruz, e a da farmacêutica Janssen são de segunda geração, com adenovírus como vetor viral para a proteína S (Spikee) do SARS-CoV-2, ${ }^{1,2,3}$. A quarta candidata testada de fase 2/3 no Brasil, das companhias BioNTech/Pfizer/Fosum Pharma, é uma vacina de nova geração, com material genético de RNA ${ }^{1,2,3}$. Até aquele momento, nenhuma vacina dessa nova geração havia sido aprovada para uso em humano ${ }^{3}$.
\end{abstract}

Pesquisadores brasileiros vêm contribuindo para o desenvolvimento de vacinas para o novo coronavírus, todas em fase pré-clínica. Três são citadas como candidatas pela Organização Mundial de Saúde: a vacina de vírus inativado em desenvolvimento pelo Instituto Butantan/Dynavax/PATH, que utiliza vírus da Doença de NewCastle quimérico expressando trímero de proteína S de SARS-CoV-2; a vacina de segunda geração da parceria Fiocruz/Instituto Butantan, com vetor viral (influenza atenuado) que também expressa porção antigênica da proteína S de SARS-CoV-2; e a nova classe de vacina, conhecida como VLPs (Virus-Like Particles), da USP, em colaboração com as Universidades de Oxford/ Inglaterra e de Berna/Suíçaa ${ }^{1,4}$.

Muitas outras abordagens inovadoras estão em andamento no Brasil. Na UFRJ, uma plataforma vacinal combina vírus vivo atenuado à edição genética (Crispr/Cas) ${ }^{5}$. No Instituto Butantan, uma vacina acelular com proteínas recombinantes de superfície do SARS-CoV-2 utiliza como matriz vesículas de membrana externa (Outer Membrane Vesicles, 
conhecidas como OMVs), com forte poder adjuvante ${ }^{6}$. Existem ainda outros exemplos de vacinas baseadas em proteínas de SARS-CoV-2. O Instituto de Tecnologia em Imunobiológicos (Bio-Manguinhos/Fiocruz) desenvolve uma vacina com peptídeos antigênicos de células B e T acoplados em nanopartículas, bem como vacina em plataforma de subunidade? Testam também vacinas com nanopartículas a $\mathrm{UFPR}^{8}$ e a startup brasileira Farmacore associada à americana PDS Biotechnology, que possui tecnologia de ativação T?

Outra abordagem explorada no Brasil é a construção de vacinas para o novo coronavírus a partir de estudos direcionados para outros alvos, gerando potenciais vacinas duplas. Uma delas, arquitetada pela Fiocruz/MG, em parceria com outras instituições, como a UFMG, o Instituto Butantan, a USP e a Faculdade de Medicina de Ribeirão Preto, utiliza o vírus influenza como vetor viral. Assim, uma vacina bivalente influenza/SARS-CoV-2 poderia ser utilizada em campanhas anuais de vacinaçã $0^{10}$. Um outro trabalho conjunto, da UFSC com a UFMG, o Instituto Butantan, e que conta ainda com a Universidade de Cambridge/Reino Unido, e o Instituto Karolinska/Suécia, visa construir uma vacina dupla que possa proteger tanto contra tuberculose como contra a COVID-19, partindo de pesquisas com BCG recombinante ${ }^{11}$.

Uma vacina para SARS-CoV-2 baseada em BCG poderá ter grandes vantagens na indução de uma resposta efetiva ao novo coronavírus. Sabe-se que a imunidade celular aos vírus depende da produção inicial de interferon tipo I (IFN-I), o que é bloqueado pelos vírus SARS-CoV-2 ${ }^{12}$. Além disso, a deficiência de IFN-I foi associada à maior gravidade da COVID-19 $9^{13,14}$. Encontrar um alvo vacinal que facilite essa resposta seria uma abordagem de interesse. A vacina BCG atende a esse requisito, pois ativa a produção de IFN-I ${ }^{15}$. Entretanto, somente estudos de fase 3 podem avalizar a vacina BCG como protetora para COVID-19.

Nesse sentido, a antiga vacina BCG tem figurado na lista de vacinas contra SARS-CoV-2, como uma vacina heteróloga ${ }^{16}$. O ensaio clínico de fase 3 BRACE, em andamento no Brasil e no mundo, visa testar a eficácia da revacinação com BCG em profissionais da saúde, na linha de frente do enfrentamento da COVID-19, quanto à proteção ou mitigação da doença ${ }^{17}$. Outras pesquisas brasileiras (REVAC-BCG) poderão contribuir para o esclarecimento de estudos ecológicos que sugerem um efeito protetor da BCG na morbimortalidade da COVID-19 ${ }^{18}$.

Devido ao grande número de casos de COVID-19, o Brasil foi inserido em testes de fase 3 de vacinas, incluso heteróloga, para o SARS-CoV-2. O fato de não haver grande resistência da população brasileira às vacinações, como ocorre em outros países, favoreceu o voluntariado nos ensaios clínicos. Será ainda um fator de grande impacto na aquisição da imunidade de rebanho, levando em conta que pesquisa de opinião aponta que a maioria dos brasileiros pretende aderir à vacinação contra o novo coronavirus ${ }^{19}$.

Efetivamente, a ampla cobertura vacinal da população é essencial para a proteção coletiva ou imunidade de rebanho, em especial com o aumento de variantes virais de SARS-CoV-2 pelo mundo e no Brasil. Para isso, é necessária a compra de vacinas do maior número possível daquelas aprovadas para uso, e no maior número de doses em menor tempo. Infelizmente, isso ainda não se concretizou no país.

Por outro lado, o Brasil conta com outro grande trunfo para o sucesso das vacinas protetoras para COVID-19, desde que disponíveis, que é o Programa Nacional de Imunizações, trazendo suporte à logística de distribuição e aplicação das doses ${ }^{20}$. Além disso, na América Latina, o Brasil é o único com grandes polos de produção de vacinas, como Biomanguinhos/Fiocruz e Instituto Butantan, já comprometidos com a fabricação em larga escala de doses das vacinas candidatas de Oxford e Sinovac para atender à população brasileira. Aliada a tudo isso, não menos importante é a contribuição de nossos cientistas brasileiros no desenvolvimento de vacinas nacionais.

\section{REFERÊNCIAS |}

1. Organização Mundial da Saúde [Internet] Draft landscape of COVID-19 candidate vacines [acesso em 14 out 2020]. Disponível em: URL: https://www.who.int/publications/m/item/draft-landscape-of-covid-19-candidate-vaccines. 
2. Agência Nacional de Vigilância Sanitária [Internet]. Covid-19: Fique por dentro do mapa das vacinas em teste no Brasil [acesso em 14 out 2020]. Disponível em: URL: https://www.gov.br/anvisa/pt-br/assuntos/noticias-anvisa/2020/fique -por-dentro-do-mapa-das-vacinas-em-teste-no-brasil.

3. Callaway EThe race for coronavirus vacines: a graphical guide. Nature. 2020; 580:576-7.

4. Alisson E. Cientistas brasileiros estão desenvolvendo vacina contra novo coronavírus. Agência FAPESP [Internet] 2020 mar 16 [acesso em 14 out 2020]. Disponível em: URL: https:/ /agencia.fapesp.br/cientistas-brasileiros-estao-desenvolvendo-vacina-contra-novo-coronavirus/32743/.

5. Azevedo AL. O Globo [Internet]. UFRJ investe em pesquisa para ter vacina brasileira contra Covid-19 2020 ago 30 [acesso em 14 out 2020]. Disponível em: URL: https://oglobo.globo.com/sociedade/ufrj-investe-em-pesquisa-para-tervacina-brasileira-contra-covid-19-24612632.

6. Ziegler MF. Pesquisadores do Butantan combinam técnicas de biotecnologia para formular vacina contra COVID-19 [Internet]. Agência FAPESP 04 maio 2020 [acesso em 14 out 2020]. Disponível em: URL: https://agencia.fapesp.br/ pesquisadores-do-butantan-combinam-tecnicas-de-biotecnologia-para-formular-vacina-contra-covid-19/33082/.

7. Fundação Oswaldo Cruz; Bio-Manguinhos [Internet]. Vacina nacional de Bio-Manguinhos/Fiocruz para novo coronavírus entrará em estudo pré-clínico [acesso em 14 out 2020]. Disponível em: URL: https://www.bio.fiocruz.br/images/ 2020-release-vacina-sintetica-coronavirus.pdf.

8. Milléo A. Ao menos cinco vacinas brasileiras estão na corrida pela imunização contra a Covid-19. Tribuna PR [nternet] 2020 ago 29 [acesso em 14 out 2020]. Disponível em: URL: https://www.tribunapr.com.br/viva/ao-menos-cinco-vacinas -brasileiras-estao-na-corrida-pela-imunizacao-contra-a-covid-19/.

9. Santos MT. Vacina brasileira entra na corrida contra o novo coronavírus. Revista Veja [Internet] 2020 ago 17 [acesso em 14 out 2020]. Disponível em: URL: https://saude.abril.com.br/medicina/vacina-brasileira-entra-na-corrida-contra-onovo-coronavirus/.

10. Fundação Oswaldo Cruz [nternet]. Fiocruz Minas participa de estudo para vacina contra Covid-19 [acesso em 14 out 2020]. Disponível em: URL: https://portal.fiocruz.br/noticia/ fiocruz-minas-participa-de-estudo-para-vacina-contracovid-19.

11. Universidade Federal de Minas Gerais [Internet]. Vacina contra a tuberculose pode ser alternativa para enfrentar o coronavírus [acesso em 14 out 2020]. Disponível em: URL: https://ufmg.br/comunicacao/noticias/vacina-contra-a-tuberculose-pode-ser-alternativa-para-enfrentar-o-coronavirus.

12. Konno Y, Kimura I, Uriu K, Fukushi M, Irie T, Koyanagi Y, et al. SARS-CoV-2 ORF3b is a potent interferon antagonist whose activity is increased by a naturally occurring elongation variant. Cell Rep. 2020; 32(12):108185.

13. Hadjadj J, Yatim N, Barnabei L, Corneau A, Boussier J, Smith N, et al. Impaired type I interferon activity and inflammatory responses in severe COVID-19 patients. Science. 2020; 369(6504):718-24.

14. Blanco-Melo D, Nilsson-Payant BE, Liu WC, Uhl S, Hoagland D, Møller R, et al. Imbalanced host response to SARSCoV-2 drives development of COVID-19. Cell. 2020; 181(5):1036-45.

15. Rivas-Santiago CE, Guerrero GG. IFN- $\alpha$ boosting of Mycobacterium bovis Bacillus Calmette Güerin-vaccine promoted Th1 type cellular response and protection against M. tuberculosis infection. Biomed Res Int. 2017; 2017:8796760.

16. Corum J, Wee SL, Zimmer C. Coronavirus vaccine tracker. The New York Times [Internet]. 2020 out 14 [acesso em 14 out 2020]. Disponível em: URL: https://www.nytimes.com/interactive/2020/science/coronavirus-vaccine-tracker. html. 
17. Clinical Trials [Internet]. BCG Vaccination to Protect Healthcare Workers Against COVID-19 (BRACE) [acesso em 14 out 2020]. Disponível em: URL: https://clinicaltrials.gov/ct2/show/NCT04327206.

18. Pereira M, Paixão E, Trajman A, Souza RA, Natividade MS, Pescarini JM, et al. The need for fast-track, high-quality and low-cost studies about the role of the BCG vaccine in the fight against COVID-19. Respir Res. 2020; 21(178).

19. Datafolha Instituto de Pesquisas [Internet]. 9\% não pretendem se vacinar contra Covid-19 [acesso em 14 out 2020]. Disponível em: URL: http://datafolha.folha.uol.com.br/opiniaopublica/2020/08/1988839-nove-em-cada-dez-9-nao -pretendem-se-vacinar-contra-covid-19.shtml.

20. Ministério da Saúde. Programa Nacional de Imunizações: 30 anos. Brasília: Ministério da Saúde; 2003 [acesso em 14 out 2020]. Disponível em: URL: http://bvsms.saude.gov.br/bvs/publicacoes/livro_30_anos_pni.pdf. 